University of Nebraska - Lincoln

DigitalCommons@University of Nebraska - Lincoln

\title{
Chronological Age-Grading of Three Species of Stored-Product Beetles by Using Near-Infrared Spectroscopy
}

Joel Perez-Mendoza

USDA-ARS

James E. Throne

USDA-ARS, Manhattan, KS, james.throne@ars.usda.gov

Floyd E. Dowell

USDA-ARS

James E. Baker

USDA-ARS

Follow this and additional works at: https://digitalcommons.unl.edu/usdaarsfacpub

Perez-Mendoza, Joel; Throne, James E.; Dowell, Floyd E.; and Baker, James E., "Chronological Age-Grading of Three Species of Stored-Product Beetles by Using Near-Infrared Spectroscopy" (2004). Publications from USDA-ARS / UNL Faculty. 2022.

https://digitalcommons.unl.edu/usdaarsfacpub/2022

This Article is brought to you for free and open access by the U.S. Department of Agriculture: Agricultural Research Service, Lincoln, Nebraska at DigitalCommons@University of Nebraska - Lincoln. It has been accepted for inclusion in Publications from USDA-ARS / UNL Faculty by an authorized administrator of DigitalCommons@University of Nebraska - Lincoln. 


\title{
Chronological Age-Grading of Three Species of Stored-Product Beetles by Using Near-Infrared Spectroscopy
}

\author{
JOEL PEREZ-MENDOZA, JAMES E. THRONE, FLOYD E. DOWELL, AND JAMES E. BAKER
}

USDA-ARS Grain Marketing and Production Research Center, 1515 College Avenue, Manhattan KS 66502

J. Econ. Entomol. 97(3): 1159-1167 (2004)

\begin{abstract}
The accuracy of near-infrared spectroscopy (NIRS) for predicting the chronological age of adults of the rice weevil, Sitophilus oryzae (L.); the lesser grain borer, Rhyzopertha dominica (F.); and the red flour beetle, Tribolium castaneum (Herbst), three pests of stored grain, was examined. NIRS-predicted age correlated well with actual age of these three species. Age predictions in S. oryzae by using the NIRS method are not dependent upon adult sex or temperatures to which adult weevils are exposed. Results indicated that water content decreased with increasing age in rice weevil adults, and excluding wavelengths at which water absorbs NIR radiation reduced the accuracy of correct classification. Additionally, removing cuticular lipids from insects resulted in a significant decrease in classification accuracy of weevils, indicating that these compounds may be partly responsible for the ability of NIRS to differentiate young from old beetles. NIRS is a nondestructive technique that can be used to age-grade large numbers of adult stored-product beetles, information that could help to increase the accuracy of population models for these pest species.
\end{abstract}

KEY WORDS Sitophilus oryzae, Rhyzopertha dominica, Tribolium castaneum, age-grading, nearinfrared spectroscopy

THE RICE WEEVIL, Sitophilus oryzae (L.) (Coleoptera: Curculionidae), and the lesser grain borer, Rhyzopertha dominica (F.) (Coleoptera: Bostrichidae), are primary pests of stored grain (i.e., they can damage intact grain kernels), especially wheat, rice, and sorghum, in the United States (Cogburn et al. 1984) and other tropical and temperate regions (Coombs and Porter 1986). Both species are long-lived and cause quality losses during storage. Similarly, adults of the secondary pest (i.e., they are unable to damage intact grain kernels), the red flour beetle, Tribolium castaneum (Herbst) (Coleoptera: Tenebrionidae), are also longlived and attack a variety of processed grain products, resulting in severe quality loss (Campbell and Hagstrum 2002). Successful management of these pests requires thorough sampling protocols and subsequent decision-making, often based on predictive population models or expert system analysis. Because oviposition by these species is not temporally uniform (Simwat and Chahal 1975, Prakash 1980, Perez-Mendoza et al. 2003), the accuracy of predictive models used to manage these species can be improved significantly if age structure of the pest populations is incorporated. However, except for S. oryzae, there is no information

Mention of trade names or commercial products in this publication is solely for the purpose of providing specific information and does not imply recommendation or endorsement by the U.S. Department of Agriculture. on methods to determine the chronological or physiological age of these coleopterans.

Age-related changes in the reproductive system in female $S$. oryzae were used to estimate weevil age (Perez-Mendoza et al. 2003). Female weevils have a pair of ovaries, each with two ovarioles of the meroistic/telotrophic type. The accumulation of follicular relics or "yellow bodies" (Grodowitz and Brewer 1987) at the base of the ovarioles was used as the basis for age determination. Although determining the percentage of a weevil population in a given parous stage can be used to estimate population age structure, this age-grading technique is hampered by the time required to perform dissections and by the confounding effect of nutritional status on oosorption by female weevils, a physiological process that also results in follicular relic accumulation. Therefore, we tested the application of near-infrared spectroscopy (NIRS) to determine the chronological age in three long-lived species of beetles that attack grain in storage facilities. We previously showed that NIRS can be used to determine chronological age of the house fly, Musca domestica L., a relatively short-lived dipteran (PerezMendoza et al. 2002). In that study, absorbance regions corresponding to $\mathrm{CH}_{3}, \mathrm{CH}_{2}$, and $\mathrm{CH}$ groups were the most important for NIRS classification of adult flies. These chemical moieties are common constituents of most insect cuticular and internal lipids, and evidence suggested that changes in amount and composition of cuticular lipids that occur during adult 
aging might be responsible for NIRS absorption differences between young and old flies (Perez-Mendoza et al. 2002). However, additional studies are needed to directly link changes in these cuticular lipids in adult insects to age classification by NIRS. The objectives of this study were to determine whether NIRS could be used to assess chronological age in adult S. oryzae, R. dominica, and T. castaneum and to determine the role of cuticular lipids of S. oryzae in this process. We also tested whether water content in adult weevils varies with age and whether NIR wavelengths that are absorbed by water influence agegrading.

\section{Materials and Methods}

Insect Cultures. Adults of S. oryzae and R. dominica used in this study were obtained from laboratory strains reared on whole kernel, hard red winter wheat, Triticum aestivum L. Adults of T. castaneum were reared on diet containing 95 parts of wheat flour and 5 parts of Brewer's yeast. Insect cultures were started by introducing 200 unsexed adults into $200 \mathrm{~g}$ of wheat and/or wheat flour, adjusted to $13.5 \%$ moisture content, in 800-ml glass jars that had screen/filter paper lids. Jars were held at $30 \pm 1{ }^{\circ} \mathrm{C}$ and $70 \pm 5 \% \mathrm{RH}$ with a photoperiod of 12:12 (L:D) h. All founding adults were removed by sieving after $4 \mathrm{~d}$. This rearing cycle was repeated biweekly for $30 \mathrm{wk}$ to produce adults with different chronological ages. Immatures were reared at $30^{\circ} \mathrm{C}$ for rapid development, but, after adult emergence, the cultures were removed from the $30^{\circ} \mathrm{C}$ rearing chamber and transferred to another chamber maintained at $20 \pm 1{ }^{\circ} \mathrm{C}, 60 \pm 5 \% \mathrm{RH}$, and a photoperiod of 12:12 (L:D) h to prolong adult longevity, so that we could obtain beetles from a broad range of ages for testing. Adults of each age group were transferred to new wheat or wheat flour every 2 wk to avoid contamination from emerging progeny.

Selection of Insects to be Scanned with NIRS. Adults with the following chronological ages were tested: rice weevil at $6,19,33,43,60,73,89$, and $103 \mathrm{~d}$ old; lesser grain borer at 1, 12, 38, 64, 92, 121, 148, 190, and $216 \mathrm{~d}$ old; and red flour beetle at $1,14,30,55,82$, $110,138,166,198$, and $227 \mathrm{~d}$ old. Rice weevils and red flour beetles were sexed by external sex differences (Halstead 1963), whereas lesser grain borers were sexed by gently squeezing the abdomen until the tip of the genitalia was exposed, and the sex was determined by observation through a microscope ("squeezing method") (Crombie 1941). Maximum age tested was based on longevity of each species at $20^{\circ} \mathrm{C}$. Groups of 100 males and 100 females from each age class per species were collected from cultures by screening and sexing. They were then frozen at $-20^{\circ} \mathrm{C}$ for $48 \mathrm{~h}$. Before scanning, frozen adults were held at room temperature for $24 \mathrm{~h}$. Those insects were used for all further studies, except the temperature study.

NIRS Data Collection. A near-infrared spectrometer (DA7000, Perten Instruments, Springfield, IL) was used to collect spectra from single insects that were placed in a V-shaped trough with their ventral surface facing the reflectance probe. An 8-mm-diameter fiberoptic probe illuminated the insect, and a 2-mm-diameter fiber-optic probe carried reflected energy from the insect to the spectrometer. The spectrometer measures absorbance from 400 to $1700 \mathrm{~nm}$ by using an array of silicon and indium-gallium-arsenide sensors and collects data at a rate of 30 spectra per second. Eight spectra were collected from each of the insects. The eight spectra were averaged to reduce noise and recorded in 5-nm increments. Dowell et al. (1999) described the spectra collection equipment.

Individual calibration models for each insect species were developed by scanning 50 adults from each sex by age combination. Each calibration model was validated by predicting the chronological age of another set of 200 males and 200 females of different known ages from each species.

Temperature. This study was conducted to determine the effect of adult exposure to different temperatures on the accuracy of age-grading by using the NIRS method. Adults of S. oryzae used in this study were obtained from a laboratory strain reared on whole kernel, hard red winter wheat. Insect culture jars were initiated by introducing 100 unsexed adults into $200 \mathrm{~g}$ of wheat, adjusted to $13.5 \%$ moisture content, in 800-ml glass jars that had screen/filter paper lids. Jars were held at $30 \pm 1^{\circ} \mathrm{C}$ and $70 \pm 5 \% \mathrm{RH}$ with a photoperiod of 12:12 (L:D) h. All founding adults were removed by sieving after $4 \mathrm{~d}$. When adult emergence started, the jars were sieved to remove emerged adults, and then the jars were returned to the rearing chamber and held for four more days. After this period, the jars were screened again and the newly emerged adults were removed and transferred to new jars containing the same amount of diet. Four jars were held at $20 \pm 1^{\circ} \mathrm{C}$, six jars were held at $25 \pm 1^{\circ} \mathrm{C}$, and eight jars were held at $30 \pm 1^{\circ} \mathrm{C}$. The three incubators were held at $70 \pm 5 \% \mathrm{RH}$ with a photoperiod of 12:12 (L:D) h. Adults of each age group were transferred to new wheat every 3 wk to avoid contamination from emerging progeny. This rearing cycle was repeated once a month for 4 mo to produce groups of adults with $30 \mathrm{~d}$ difference in chronological age.

Adults with the following chronological ages were tested: 1-3, 29-32, 59-62, and 88-91 d old. Groups of 50 male and 50 female adults from each age class per temperature were collected from cultures by screening and then frozen at $-20^{\circ} \mathrm{C}$ for $24 \mathrm{~h}$. Because of reduced longevity of females, we only collected males at the oldest age (88-91 d old) from the three temperatures. Before scanning, frozen adults were held at room temperature for $24 \mathrm{~h}$. Individual and combined calibration models for each sex and temperature were developed by scanning 50 adults from each sex by age by temperature combination. Each calibration model was validated by predicting the chronological age of another set of 200 males and 200 females of different known ages.

Cuticular Lipids. To test the hypothesis that surface lipids may influence ability to age-grade by NIRS, three groups of 50 male and 50 female rice weevil adults $(6,33$, and $73 \mathrm{~d}$ old $)$ were scanned. Subse- 
quently, cuticular lipids were extracted from adult weevils, and the extracted insects were scanned again. The extraction procedure consisted of rinsing each group of 50 insects four times ( 2 min per rinse) with hexane (Baker et al. 1984).

Water Content. This study was conducted to determine whether water content in adult weevils varies with age, and whether excluding NIR wavelengths that are absorbed by water from the calibration model may increase or decrease its accuracy to predict age. Groups of 10 live male and 10 live female weevils (12, $25,49,66$, and $95 \mathrm{~d}$ old) were placed in individual tared aluminum dishes (with covers) and weighed. The dishes were placed in a mechanical convection oven (model no. HTM 85, Precision Scientific Inc., Chicago, IL) held at $70^{\circ} \mathrm{C}$. After $24 \mathrm{~h}$, the dishes were removed, allowed to cool to room temperature, and reweighed. Three replicates for each sex by age combination were used to determine moisture content.

Statistical Analysis. We used a relative age scale, rather than days, in the analyses because the three species live for different lengths of time when reared at the same temperature. Thus, an insect of age 0 is a newly emerged adult, and an insect of age 1 has reached its maximum life span in these laboratory tests. The relative age scale was determined by dividing the age of the beetles by the maximum age tested for each species. Thus, reported relative ages can be converted back to chronological age by multiplying by the maximum age tested for each species.

Paired and multiple-comparison statistical analyses were performed on NIR spectral data by using partial least squares (PLS) regression (Galactic Industries 1996). The PLS regression takes advantage of the correlation between the reflectance data at each wavelength and constituent concentrations. In paired comparisons, all combinations of ages were paired and analyzed. Cross-validation was used to determine classification accuracy. Results are presented as the classification accuracy and the coefficient of determination when the optimum number of PLS factors was used. The number of factors selected was based on the reduction in residual sum of squares achieved by adding PLS factors to the calibration models. The $r^{2}$ is the proportion of the sum of squares of the predicted age that can be attributed to the known age. The PLS regression reports the importance of absorbance spectral wavelength bands used in calibrations as beta coefficients. For any given spectral wavelength band, the absolute value of the beta coefficient indicates how important that spectral wavelength band was for classification. An age prediction is obtained by multiplying the absorbance at each spectral wavelength band by the corresponding beta coefficient, and then summing each of those products across all spectral wavelength bands. Thus, the beta coefficients represent the calibration model. The number of beta coefficients does not change as the number of factors changes. The spectral region from 470 to $1700 \mathrm{~nm}$ was analyzed.

The relationship between NIRS-predicted age and actual age was determined by linear regression
(PROC REG, SAS Institute 1998). The effect of sex and temperature on the slopes of these regressions and variations in water content in adult weevils were analyzed by using analysis of variance (ANOVA) (PROC ANOVA, SAS Institute 1998).

Calibration models were developed with the PLS software for each species. For the temperature study, calibration models were developed for each level of each factor studied (sex and temperature). More complex calibration models were developed by combining across all levels of each factor studied. Finally, a combined calibration model that included sexes and temperatures was developed. The performance of the models was evaluated by using the validation sets. We selected the best models by examining $r^{2}$ values, confidence limits on predicted ages, and classification accuracy from the validation sets. Classification accuracy refers to percentage of insects from a validation set classified correctly based on NIRS-predicted age \pm confidence limits on predicted ages. In the case of the effect of cuticular lipids, we conducted independent validations of the calibration models by using the calibration model from unextracted weevils with cuticular lipids to predict age of extracted weevils without cuticular lipids and vice versa.

\section{Results}

\section{Development of Calibration Models}

Results obtained when correlating absorbance to adult chronological age showed that little or no classification information resulted from absorbance in the visible or very near infrared region $(<650 \mathrm{~nm})$ in these three species of stored-product pests. A comparison of classification accuracies $\left(r^{2}\right.$ and standard error values) and confidence limits on predicted ages resulting from calibrations with and without these regions confirmed this observation (Table 1). Including wavelengths below $650 \mathrm{~nm}$ did not improve classification; therefore, they were not used in development of final calibration models.

There was a strong relationship between NIRS-predicted age and relative chronological age for all three species (S. oryzae: $F=371.1 ; \mathrm{df}=8,715 ; P<0.01 ; R$. dominica: $F=464.4 ; \mathrm{df}=8,857 ; P<0.01$; and $T$. castaneum: $F=570.0 ; \mathrm{df}=9,958 ; P<0.01)$. Sex did not affect the ability to predict age (S. oryzae: $F=0.03$; $\mathrm{df}=1,715 ; P=0.87 ; R$. dominica: $F=0.01 ; \mathrm{df}=1,857$; $P=0.94 ;$ and T. castaneum: $F=0.02 ; \mathrm{df}=1,958 ; P=$ $0.95)$. The interaction for age by sex also was not significant $(S$. oryzae: $F=3.0 ; \mathrm{df}=8,715 ; P=0.06 ; R$. dominica: $F=1.6 ; \mathrm{df}=8,857 ; P=0.12$; and T. castaneum: $F=1.7 ; \mathrm{df}=9,958 ; P=0.08)$. Therefore, regressions between NIRS-predicted age and relative chronological age were conducted for mixed sexes in each species (Table 2). Confidence limits of the NIRSpredicted ages were similar in the models developed for each of the three species (Table 2). Confidence limits indicated that beetles in the first third of their lives could be differentiated from those in the last third of their lives. Classification accuracy in the validation tests ranged from 82 to $92 \%$. 
Table 1. Comparison of classification results by using different wavelength ranges

\begin{tabular}{lccccc}
\hline \multicolumn{1}{c}{ Species } & $\begin{array}{c}\text { Wavelength } \\
\text { range }(\mathrm{nm})\end{array}$ & $\begin{array}{c}\text { No. of } \\
\text { factors }^{a}\end{array}$ & $r^{2}$ & SEP & $\begin{array}{c}\text { Confidence } \\
\text { limits }^{b}\end{array}$ \\
\hline S. oryzae & $470-1,700$ & 7 & 0.54 & 0.200 & 0.460 \\
& $650-1,700$ & 7 & 0.80 & 0.130 & 0.287 \\
R. dominica & $470-1,700$ & 13 & 0.71 & 0.178 & 0.393 \\
& $650-1,700$ & 13 & 0.79 & 0.152 & 0.316 \\
T. castaneum & $470-1,700$ & 7 & 0.69 & 0.183 & 0.363 \\
& $650-1,700$ & 7 & 0.75 & 0.165 & 0.306 \\
\hline
\end{tabular}

SEP, standard error of a prediction.

${ }^{a}$ Number of classification factors in the partial least squares regression analysis.

${ }^{b}$ Relative age scale.

Table 2. Relationship between NIRS-predicted age and relative chronological age, and classification accuracy of predicted age in three species of stored-product beetles

\begin{tabular}{lccccc}
\hline \hline \multirow{2}{*}{ Species } & \multicolumn{2}{c}{ Equation parameters } & \multicolumn{2}{c}{$\begin{array}{c}\text { 95\% CL of } \\
\text { predicted age }\end{array}$} & $\begin{array}{c}\text { Correct } \\
\text { classification } \\
\text { rate }(\%)\end{array}$ \\
\cline { 2 - 5 } & $\mathrm{a} \pm \mathrm{SE}$ & $\mathrm{b} \pm \mathrm{SE}$ & $r^{2}$ & 0.29 & 82.7 \\
S. oryzae & $0.098 \pm 0.01$ & $0.79 \pm 0.015$ & 0.80 & 0.32 & 86.9 \\
R. dominica & $0.094 \pm 0.01$ & $0.80 \pm 0.014$ & 0.79 & 0.31 & 91.9 \\
T. castaneum & $0.110 \pm 0.01$ & $0.75 \pm 0.014$ & 0.75 & 0.31 & \\
\hline
\end{tabular}

Relationship is $\mathrm{y}=\mathrm{a}+\mathrm{bx}$, where $\mathrm{y}$ is NIRS-predicted age, $\mathrm{x}$ is actual age, and $r^{2}$ is the percentage variation in $\mathrm{y}$ accounted for by using a linear model. Age is reported in a relative age scale from 0 to 1.

The beta coefficient plots from the three species indicated that absorption peaks corresponding to $\mathrm{CH}$ and $\mathrm{OH}$ functional groups contributed most to classifications by NIRS (Murray and Williams 1990) (Fig. 1 ). Wavelengths corresponding to the first, second, and third $\mathrm{CH}$ absorption overtones of $\mathrm{CH}_{3}$ and $\mathrm{CH}_{2}$ groups and the first combination $\mathrm{CH}$ absorption overtones $(850-980,1,120-1,225,1,350-1,450$, and $1,650-$ $1,700 \mathrm{~nm}$ ), as well as wavelengths corresponding to the first, second, and third $\mathrm{OH}$ absorption overtones of $\mathrm{H}_{2} \mathrm{O}$ groups $(700-800,960-1,150$, and $1,350-1,500$ $\mathrm{nm}$ ), are likely responsible for the ability to differentiate young and old beetles by using NIRS (Murray and Williams 1990).

\section{Influence of Temperature on NIRS Age-Grading}

Individual Models. The relationship between NIRSpredicted age and actual age for weevils was significantly different among temperatures $(F=4.3 ; \mathrm{df}=2$, $948 ; P=0.01)$ and sexes $(F=17.4 ; \mathrm{df}=1,948 ; P<0.01)$ (Fig. 2A and B). The interactions for age by temperature $(F=2.8 ; \mathrm{df}=6,948 ; P<0.01)$ and age by sex $(F=20.6 ; \mathrm{df}=2,948 ; P<0.01)$ were also significant. Therefore, separate regressions were fit for each sex and temperature (Table 3). However, the slopes of the regressions in Table 3 were homogeneous among temperatures for both males $(F=0.6 ; \mathrm{df}=2,511 ; P=0.6)$ and females $(F=0.3 ; \mathrm{df}=2,437 ; P=0.7)$, and for both

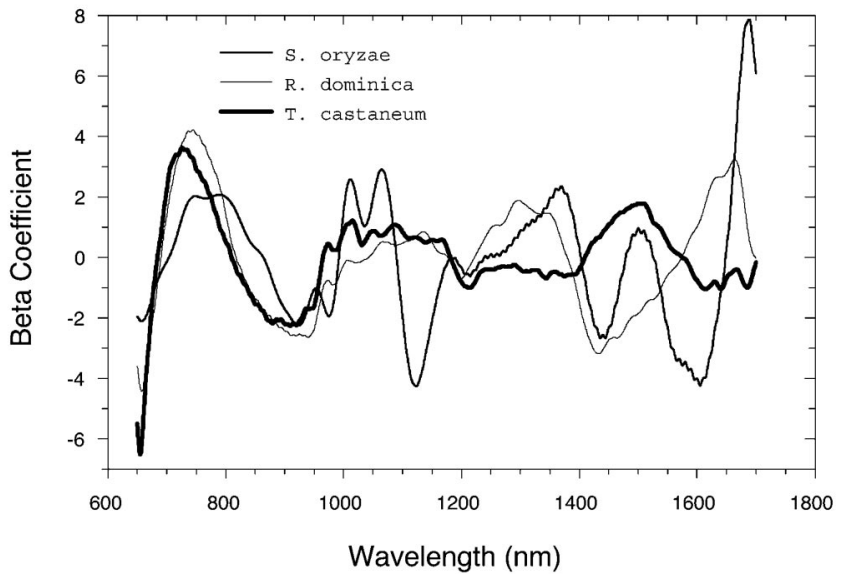

Fig. 1. Beta coefficients showing important spectral wavelength bands used by partial least square calibrations to age-grade the three species of stored-product pests with NIRS (spectra obtained from the calibration models [five factors]). 

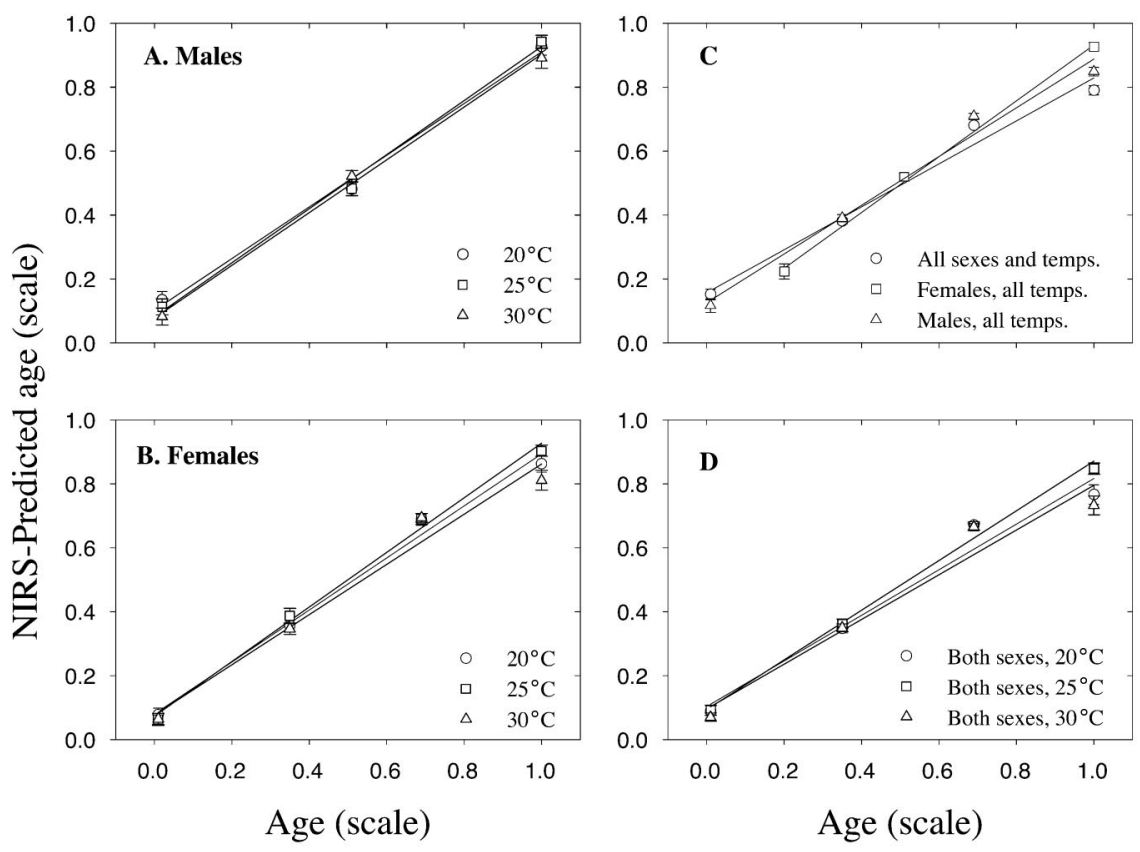

Fig. 2. Relationship between NIRS-predicted age and actual age of individual calibration models (A and B) and combined calibration models $(\mathrm{C}$ and $\mathrm{D})$.

sexes at $20^{\circ} \mathrm{C}(F=0.7 ; \mathrm{df}=1,308 ; P=0.4), 25^{\circ} \mathrm{C}(F=$ $0.07 ; \mathrm{df}=1,328 ; P=0.8)$, and $30^{\circ} \mathrm{C}(F=0.3 ; \mathrm{df}=1,282$; $P=0.6)$. Confidence limits of the NIRS-predicted ages were smaller for the models developed using data from males than for the models developed using data from females. Classification accuracy in the validation tests tended to be higher with models developed using data from males (Table 3).

Combined Models. These calibration models were generated by combining data for all levels of each factor studied to determine whether one needs to know weevil sex and/or temperature at which adult weevils were maintained to determine their chronological age by using NIRS. The relationship between NIRS-predicted age and actual age was significantly different among combined models $(F=16.5 ; \mathrm{df}=5$, 2444; $P<0.01$ ) (Fig. 2C and D). The interaction for age by model was also significant $(F=2.0 ; \mathrm{df}=15$, $2444 ; P=0.04)$. Therefore, separate regressions were fit for each combined model (Table 4). The slopes of the regressions in Table 4 were heterogeneous $(F=$ 12.5; $\mathrm{df}=5,2444 ; P<0.01)$. Confidence limits on predicted ages were similar among the different combined models, with the exception of females, all temperatures $(0.40)$ and both sexes at $30^{\circ} \mathrm{C}(0.30)$. Therefore, one can use NIRS to differentiate rice weevil adults in the first third of their lives from those in the last third of their lives without knowing sex or the temperature at which the weevils were exposed. The rates of correct age classification in the validation tests were higher when using the combined calibration models than the rates of correct classification of the calibration models developed for a single factor. Among the combined models, the model that com-

Table 3. Relationship between NIRS-predicted age and actual age, confidence limits, and classification accuracy of predicted age in male and female adult rice weevils exposed to three temperature regimes (individual models)

\begin{tabular}{|c|c|c|c|c|c|c|}
\hline \multirow{2}{*}{$\begin{array}{l}\text { Temperature } \\
\left({ }^{\circ} \mathrm{C}\right)\end{array}$} & \multirow{2}{*}{ Sex } & \multicolumn{3}{|c|}{ Equations parameters } & \multirow{2}{*}{$95 \% \mathrm{CL}^{a}$} & \multirow{2}{*}{$\begin{array}{c}\text { Correct } \\
\text { classification } \\
\text { rate }(\%)\end{array}$} \\
\hline & & $\mathrm{a} \pm \mathrm{SE}$ & $\mathrm{b} \pm \mathrm{SE}$ & $r^{2}$ & & \\
\hline \multirow[t]{2}{*}{20} & M & $0.076 \pm 0.02$ & $0.83 \pm 0.03$ & 0.81 & 0.33 & 64.3 \\
\hline & $\mathrm{F}$ & $0.100 \pm 0.02$ & $0.81 \pm 0.04$ & 0.78 & 0.41 & 69.8 \\
\hline \multirow[t]{2}{*}{25} & M & $0.073 \pm 0.02$ & $0.86 \pm 0.03$ & 0.84 & 0.31 & 72.4 \\
\hline & $\mathrm{F}$ & $0.080 \pm 0.02$ & $0.85 \pm 0.03$ & 0.83 & 0.36 & 65.8 \\
\hline \multirow[t]{2}{*}{30} & M & $0.063 \pm 0.01$ & $0.85 \pm 0.03$ & 0.83 & 0.29 & 64.3 \\
\hline & $\mathrm{F}$ & $0.077 \pm 0.02$ & $0.83 \pm 0.04$ & 0.80 & 0.38 & 59.6 \\
\hline
\end{tabular}

F, female; M, male.

Relationship is $\mathrm{y}=\mathrm{a}+\mathrm{bx}$; where $\mathrm{y}$ is NIR-predicted age (index), $\mathrm{x}$ is actual age (index), and $r^{2}$ is the percentage variation in $\mathrm{y}$ accounted for by using a linear model.

${ }^{a}$ Confidence limits of predicted age (life index). 
Table 4. Relationship between NIRS-predicted age and actual age, confidence limits, and classification accuracy of predicted age in adult rice weevils from combined models

\begin{tabular}{|c|c|c|c|c|c|}
\hline \multirow{2}{*}{ Model } & \multicolumn{3}{|c|}{ Equations parameters } & \multirow{2}{*}{$95 \% \mathrm{CL}^{a}$} & \multirow{2}{*}{$\begin{array}{c}\text { Correct } \\
\text { classification } \\
\text { rate }(\%)\end{array}$} \\
\hline & $\mathrm{a} \pm \mathrm{SE}$ & $\mathrm{b} \pm \mathrm{SE}$ & $r^{2}$ & & \\
\hline All sexes and temperatures & $0.143 \pm 0.01$ & $0.72 \pm 0.02$ & 0.76 & 0.35 & 84.7 \\
\hline Males, all temperatures & $0.135 \pm 0.01$ & $0.76 \pm 0.03$ & 0.75 & 0.35 & 76.7 \\
\hline Females, all temperatures & $0.164 \pm 0.02$ & $0.75 \pm 0.03$ & 0.74 & 0.40 & 74.2 \\
\hline Both sexes, $20^{\circ} \mathrm{C}$ & $0.088 \pm 0.01$ & $0.78 \pm 0.02$ & 0.76 & 0.36 & 79.0 \\
\hline Both sexes, $25^{\circ} \mathrm{C}$ & $0.089 \pm 0.01$ & $0.80 \pm 0.02$ & 0.78 & 0.35 & 84.0 \\
\hline Both sexes, $30^{\circ} \mathrm{C}$ & $0.070 \pm 0.01$ & $0.81 \pm 0.02$ & 0.80 & 0.30 & 53.6 \\
\hline
\end{tabular}

Relationship is $\mathrm{y}=\mathrm{a}+\mathrm{bx}$, where $\mathrm{y}$ is NIR-predicted age (index), $\mathrm{x}$ is actual age (index), and $r^{2}$ is the percentage variation in $\mathrm{y}$ accounted for by using a linear model.

${ }^{a}$ Confidence limits of predicted age (life index).

Table 5. Effect of extraction of cuticular lipids from S. oryzae on NIRS classification of weevil age

\begin{tabular}{lcccc}
\hline \hline \multirow{2}{*}{ Model } & \multicolumn{2}{c}{ Equation parameters } & $\begin{array}{c}\text { 95\% CL of predicted } \\
\text { relative age }\end{array}$ \\
\cline { 2 - 5 } & $\mathrm{a} \pm \mathrm{SE}$ & $\mathrm{b} \pm \mathrm{SE}$ & $r^{2}$ & 0.314 \\
Unextracted & $0.081 \pm 0.02$ & $0.842 \pm 0.03$ & 0.83 & 0.519 \\
Extracted & $0.157 \pm 0.02$ & $0.691 \pm 0.03$ & 0.67 & \\
\hline
\end{tabular}

Relationship is $\mathrm{y}=\mathrm{a}+\mathrm{bx}$, where $\mathrm{y}$ is NIRS-predicted age, $\mathrm{x}$ is actual age, and $r^{2}$ is the percentage variation in $\mathrm{y}$ accounted for by using a linear model. Age is reported in a relative age scale from 0 to 1.

bines both sexes and the three temperatures yielded the highest rate of correct classification in the validation tests (Table 4 ).

\section{Influence of Cuticular Lipids on NIRS Age-Grading}

There was a strong relationship between NIRS-predicted age and actual age for the two calibration models developed with unextracted weevils $(F=503.3$; df $=2,224 ; P<0.01)$ and hexane-extracted weevils $(F=257.4 ; \mathrm{df}=2,224 ; P<0.01)$. Separate regressions were fit for each group of insects (Table 5 ). The slopes $(F=12.4 ; \mathrm{df}=1,423 ; P<0.01)$ and intercepts $(F=$ $7.8 ; \mathrm{df}=1,423 ; P<0.01)$ of the two regressions were significantly different. However, confidence limits were smaller, and $r^{2}$ value was higher for the calibration model developed with unextracted weevils than for the model developed with hexane-extracted weevils (Table 5). When the calibration model developed from unextracted weevils was validated with the data set from hexane-extracted weevils, the average rate of correct classification was $78.7 \%$. In contrast, when the calibration model developed from lipid-extracted weevils was validated with the data set from unextracted weevils, the average rate of correct classification was only $44.5 \%$. The calibration model developed from unextracted weevils was more robust and accurate for predicting age of independent samples.

The difference spectrum (Fig. 3) indicates where absorbance of NIR radiation by weevils with and without cuticular lipids may be unique. The difference spectrum shows higher absorbance at all wavelengths above $900 \mathrm{~nm}$ for the unextracted weevils. Maximum differences between unextracted weevils and hexaneextracted weevils occurred at 961, 979, and 1,699 nm (Fig. 3B). These wavelengths are assigned to lipids (third and first overtones of $\mathrm{CH}_{2}$ and $\mathrm{CH}_{3}$ groups) (Williams and Norris 1990).

\section{Effect of Water Content on NIRS Age-Grading}

Water content in adult $S$. oryzae varied significantly with age $(F=3.5 ; \mathrm{df}=4,29 ; P<0.02)$, but not with $\operatorname{sex}(F=0.03 ; \mathrm{df}=1,29 ; P=0.87)$. The interaction of
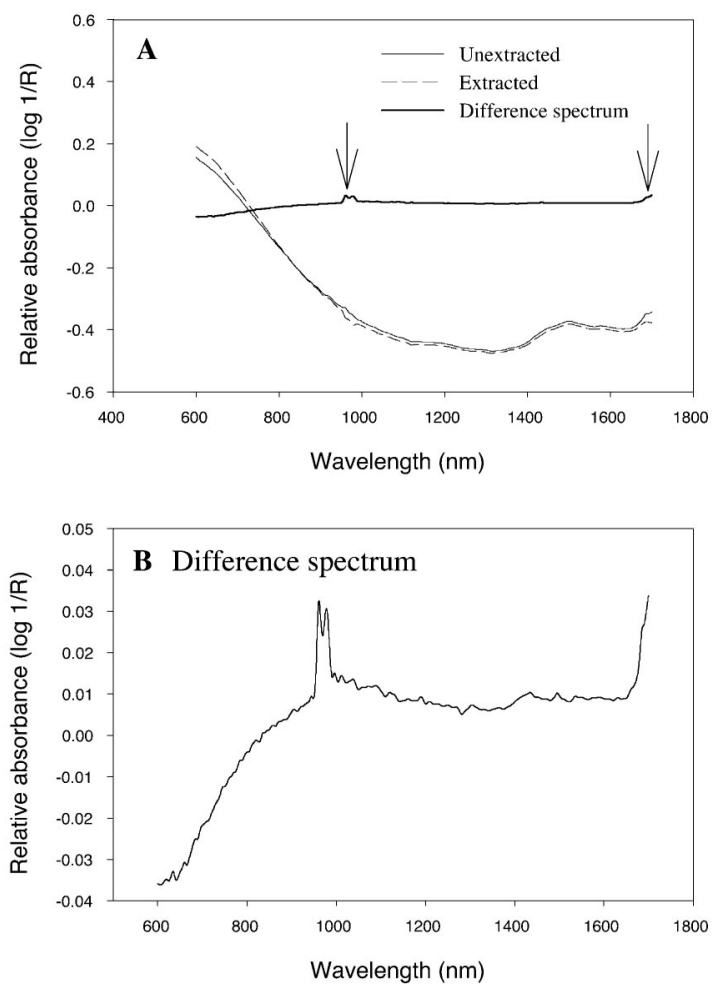

Fig. 3. (A) Difference spectrum and typical absorption spectra of weevils with and without cuticular lipids. (B) Region between arrows on Fig. 3A magnified to show detail 


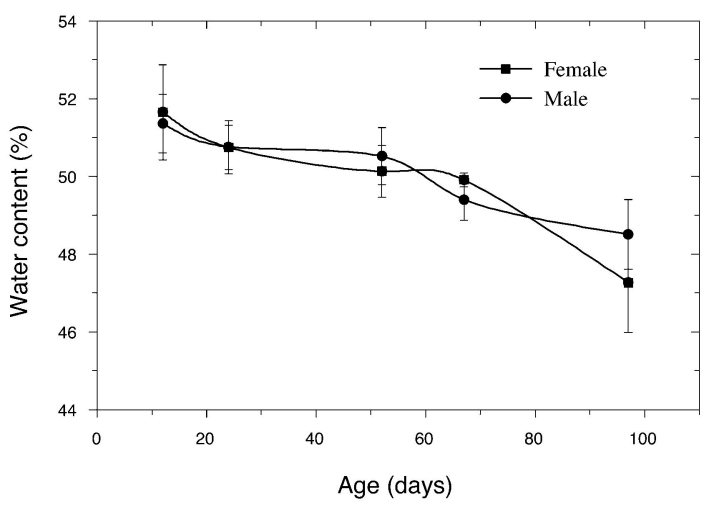

Fig. 4. Relationship between water content (mean \pm SEM) and chronological age in adult male and female rice weevils.

age and sex was not significant $(F=0.3 ; \mathrm{df}=4,29 ; P=$ $0.88)$. Younger weevils tended to have higher water content than older weevils in both males and females (Fig. 4). Excluding wavelengths associated with $\mathrm{H}_{2} \mathrm{O}$ $(650-800,900-1000,1,100-1,200$, and $1,350-1,550 \mathrm{~nm})$ from the NIRS models slightly decreased the $r^{2}$ value, increased the value of confidence limits, and decreased the accuracy of classification (Table 6).

\section{Discussion}

Populations of adult insects from laboratory cultures of S. oryzae, R. dominica, and T. castaneum used in these tests lived for $\approx 103,216$, and $227 \mathrm{~d}$, respectively, at $20^{\circ} \mathrm{C}$. When these life spans are normalized on a scale from 0 to 1 , the confidence limits of predicted relative chronological age for unsexed adults of each species by NIRS are about \pm 0.3 . Although these confidence limits are large, younger adults within the first third of their life span can be easily differentiated from older adults of each species with NIRS. Although older adults of these species continue to oviposit, younger females, i.e., those in the first third of their life span, oviposit at a higher rate (Birch 1945, Evans 1982, Longstaff and Evans 1983, Li and Arbogast 1991). As a result, the ability to differentiate between young and old adults can provide knowledge of population age structure, which will improve the accuracy of population growth models for each of these pest species.

Adult sex and field temperatures to which rice weevil adults have been exposed do not need to be known if these variables have been included in developing the calibration model. Our independent validation studies showed that when we combined across all levels of temperature and sex, the rate of correct age classification was higher than the rates of correct weevil classification from models developed for one or two levels of factors (Tables 3 and 4). Therefore, we would suggest using a composite sample of both sexes of weevils or beetles exposed at different temperatures to develop a robust calibration model.

Confident limits for age determination in our study were similar to those reported by Perez-Mendoza et al. (2003) for adult female S. oryzae with the follicular relic methods ( $\pm 0.283-0.317$ when converted to a relative chronological age scale). Confidence limits for the short-lived house fly were also very similar $( \pm 0.26)$ with the NIRS methods when converted to a relative chronological age scale (Perez-Mendoza et al. 2002). Other age-grading studies have not reported confidence limits on predictions.

NIR absorbance decreased in older adults for the three species (data not shown), giving a slightly asymptotic relationship with insect age. The same decrease in NIR absorbance in older adults was also observed in a previous study with house flies (PerezMendoza et al. 2002). Because NIR has a strong absorbance with $\mathrm{H}_{2} \mathrm{O}$ (Shenk et al. 1992), decreased absorbance may be related to the loss of water content in older adults. In our studies, excluding wavelengths associated with $\mathrm{H}_{2} \mathrm{O}$ absorbance reduced the percentage of correct age classifications. These results indicate that water apparently influences NIRS age predictions.

Based on beta coefficients, absorbance regions (peaks) corresponding to $\mathrm{CH}_{3}, \mathrm{CH}_{2}$, and $\mathrm{CH}$ groups were the most important for NIRS classification of insect age in these three beetles (Murray and Williams 1990). These methyl groups are common constituents of most insect cuticular and internal lipids. Our results provide evidence that these compounds also have a significant role in NIR absorption and NIR-based classification. In particular, the calibration model developed with rice weevils in which the cuticular lipids were removed by hexane extraction performed very poorly in classifying by age. In addition, the difference spectrum, calculated by subtracting spectra of unextracted rice weevils from the spectra of the same rice weevils without cuticular lipids, with peaks occurring at the $\mathrm{CH}_{2}$ and $\mathrm{CH}_{3}$ overtones $(\approx 961,979$, and 1,699

Table 6. Effect of water composition changes in S. oryzae on NIRS classification of weevil age

\begin{tabular}{|c|c|c|c|c|c|}
\hline \multirow{2}{*}{$\operatorname{Model}^{a}$} & \multicolumn{3}{|c|}{ Equation parameters } & \multirow{2}{*}{$\begin{array}{l}95 \% \mathrm{CL} \text { of } \\
\text { predicted } \\
\text { relative age }\end{array}$} & \multirow{2}{*}{$\begin{array}{c}\text { Correct } \\
\text { classification } \\
\text { rate }(\%)\end{array}$} \\
\hline & $\mathrm{a} \pm \mathrm{SE}$ & $\mathrm{b} \pm \mathrm{SE}$ & $r^{2}$ & & \\
\hline With water & $0.094 \pm 0.01$ & $0.802 \pm 0.01$ & 0.80 & 0.287 & 82.7 \\
\hline Without water & $0.103 \pm 0.01$ & $0.784 \pm 0.02$ & 0.78 & 0.304 & 64.3 \\
\hline
\end{tabular}

Relationship is $\mathrm{y}=\mathrm{a}+\mathrm{bx}$, where $\mathrm{y}$ is NIRS-predicted age, $\mathrm{x}$ is actual age, and $r^{2}$ is the percentage variation in $\mathrm{y}$ accounted for by using a linear model. Age is reported in a relative age scale from 0 to 1 .

${ }^{a}$ Model results with or without data from wavelengths at which water absorbs radiation in the near-infrared region. 
$\mathrm{nm})$, implicated the effect of lipids in the classification process (Williams and Norris 1990).

Changes in total lipid or lipid composition as a function of adult insect age are common. For example, changes in the amount and composition of cuticular lipids in aging insects have been documented in Diptera (Jackson and Bartelt 1986, Trabalon et al. 1992), grasshoppers (Tregenza et al. 2000), and ants (Cuvillier-Hot et al. 2001). The cuticular lipids of S. oryzae consist primarily of $n$-alkanes, $n$-alkenes, and $n$-alkadienes (Baker et al. 1984), but we do not know whether age-related changes in total amount of lipid or composition of these components occur in this long-lived species. Similarly, little is known of agerelated changes in cuticular lipids in $R$. dominica or $T$. castaneum. Nevertheless, beta coefficients associated with lipids are important in age classification and may indicate that lipid composition in these beetles does change with time.

The dynamics of aging in insects are complex (Sohal 1985). Age-related changes occur in cuticle, muscle tissue, fat body, and the reproductive, digestive, excretory, and nervous systems. In addition, there is a general reduction in metabolism and associated enzyme activities, a reduction in glycogen levels, and an increase in the presence of lipofuscin granules. These and other biochemical changes are represented in the total reflectance spectra observed during NIRS. Thus, as would be expected, despite the importance of surface lipids in age classification of the beetles used in the current study, beta coefficients indicate that changes in other components also contribute significantly to the classification process.

Our studies indicate that with appropriate calibrations, NIRS can be used to age-grade long-lived beetles. For researchers to use this technology, an NIR spectrophotometric system with a fiber optic probe should be obtained. As suggested by Perez-Mendoza et al. (2002), each instrument will need to be calibrated independently but the PLS beta coefficients should be similar to those reported in the current study.

\section{Acknowledgments}

We thank Ann Redmon for excellent technical assistance. We also thank Thomas W. Phillips (Department of Entomology, Oklahoma State University) and Michael Toews (Department of Grain Science and Industry, Kansas State University) for comments and suggestions on an earlier version of the manuscript.

\section{References Cited}

Baker, J. E., S. M. Woo, D. R. Nelson, and C. L. Fatland. 1984. Olefins as major components of epicuticular lipids of three Sitophilus weevils. Comp. Biochem. Physiol. 77B: 877-884.

Birch, L. C. 1945. The influence of temperature, humidity and density on the oviposition of the small strain of Calandra oryzae L. and Rhyzopertha dominica Fab. (Coleoptera). Aust. J. Exp. Biol. Med. Sci. 23: 197-203.
Campbell, J. F., and D. W. Hagstrum. 2002. Patch exploitation by Tribolium castaneum: movement patterns, distribution, and oviposition. J. Stored Prod. Res. 38: 55-68.

Cogburn, R. R., W. E. Burkholder, and H. J. Williams. 1984. Field tests with the aggregation pheromone of the lesser grain borer (Coleoptera: Bostrichidae). Environ. Entomol. 13: 162-166.

Coombs, C. W., and J. E. Porter. 1986. Some factors affecting the infestation of wheat and maize by Sitophilus oryzae (L.) and Sitophilus zeamais Mots. (Coleoptera: Curculionidae). J. Stored Prod. Res. 22: 33-41.

Crombie, A. C. 1941. On oviposition, olfactory conditioning and host selection in Rhyzopertha dominica Fab. (Insecta: Coleoptera). J. Exp. Biol. 18: 62-79.

Cuvillier-Hot, V., C. Matthew, C. Malosse, and C. Peeters. 2001. Sex, age and ovarian activity affect cuticular hydrocarbons in Diacamma ceylonense, a queenless ant. J. Insect Physiol. 47: 485-493.

Dowell, F. E., J. E. Throne, D. Wang, and J. E. Baker. 1999. Identifying stored grain insects using near-infrared spectroscopy. J. Econ. Entomol. 92: 165-169.

Evans, D. E. 1982. The influence of temperature and grain moisture content on the intrinsic rate of increase of Sitophilus oryzae (L.) (Coleoptera: Curculionidae). J. Stored Prod. Res. 18: 55-66.

Galactic Industries. 1996. Grams/32 user's guide, version 4.0. Galactic Industries Corp., Salem, NH.

Grodowitz, M. J., and F. D. Brewer. 1987. Ovarian anatomy and physiological age grading of the female boll weevil, Anthonomus grandis grandis Boheman (Coleoptera: Curculionidae). Ann. Entomol. Soc. Am. 80: 642-651.

Halstead, D.G.H. 1963. External sex differences in storedproduct Coleoptera. Bull. Entomol. Res. 54: 119-134.

Jackson, L. L., and R. J. Bartelt. 1986. Cuticular hydrocarbons of Drosophila virilis comparison by age and sex. Insect Biochem. 16: 433-439.

Li, L., and R. T. Arbogast. 1991. The effect of grain breakage on fecundity, development, survival, and population increase in maize of Tribolium castaneum (Herbst) (Coleoptera: Tenebrionidae). J. Stored Prod. Res. 27: 87-94.

Longstaff, B. C., and D. E. Evans. 1983. The demography of the rice weevil, Sitophilus oryzae (L.) (Coleoptera: Curculionidae), submodels of age-specific survivorship and fecundity. Bull. Entomol. Res. 73: 333-344.

Murray, I., and P. C. Williams. 1990. Chemical principles of near-infrared technology, pp. 17-34. In P. C. Williams and K. H. Norris [eds.], Near-infrared technology in the agricultural and food industries. American Association of Cereal Chemists, St. Paul, MN.

Perez-Mendoza, J., F. E. Dowell, A. B. Broce, J. E. Throne, R. A. Wirtz, F. Xie, J. A. Fabrick, and J. E. Baker. 2002. Chronological age-grading of house flies by using nearinfrared spectroscopy. J. Med. Entomol. 39: 499-508.

Perez-Mendoza, J., J. E. Throne, and J. E. Baker. 2003. Ovarian physiology and age-grading in the rice weevil (Coleoptera: Curculionidae). J. Stored Prod. Res. 40: 179196.

Prakash, A. 1980. Influence of age on fecundity and fertility of lesser grain borer, Rhyzopertha dominica F. and rice weevil, Sitophilus oryzae L. in stored rice. Bull. Grain Tech. 18: 119-121.

SAS Institute. 1998. The SAS system version 7 for Windows. SAS Institute, Cary, NC.

Shenk, J. S., J. J. Workman Jr., and M. O. Westerhaus. 1992. Application of NIR spectroscopy to agricultural products, pp. 383-431. In D. A. Burns and E. W. Ciurczak [eds.], Handbook of near-infrared analysis. Marcel Decker, Inc., New York. 
Simwat, G. S., and B. S. Chahal. 1975. Effect of the age of Tribolium castaneum Herbst (Coleoptera: Tenebrionidae) on the rate of egg laying and fecundity. Bull. Grain Tech. 13: 23-25.

Sohal, R. S. 1985. Aging in insects, pp. 596-631. In G. A. Kerhut and L. I. Gilbert [eds.], Comprehensive insect physiology, biochemistry, and pharmacology. Pergamon, Oxford, United Kingdom.

Trabalon, M., M. Campan, J. L. Clement, C. Lange, and M. T. Miquel. 1992. Cuticular hydrocarbons of Calliphora vomitoria (Diptera)-relation to age and sex. Gen. Comp. Endocrinol. 85: 208-216.
Tregenza, T., S. H. Buckley, V. L. Pritchard, and R. K. Butlin. 2000. Inter- and intrapopulation effects of sex and age on epicuticular composition of meadow grasshopper, Chorthippus parallelus. J. Chem. Ecol. 26: 257-277.

Williams, P.C., and K. H. Norris. 1990. Qualitative applications of near-infrared reflectance spectroscopy, pp. 241-288. In P. C. Williams and K. H. Norris [eds.], Near-infrared technology in the agricultural and food industries. American Association of Cereal Chemists, St. Paul, MN.

Received 20 May 2003; accepted 5 February 2004. 